\title{
INCIDENCES OF DYSTOPIA CANTHORUM AND SOME OTHER SIGNS IN A FAMILY WITH WAARDENBURG SYNDROME TYPE I
}

\author{
Makoto Yoshino, Mitsuyoshi NaKao, Yuko ShIotsuki, Atsushi NishiYori, \\ Fumio Yamashita, Shigeru Karukaya, ${ }^{1}$ Hiromi Yoshimura, \\ Hiroshi Nishida, Nobuyuki Shiotani, and Arata Sugita ${ }^{2}$ \\ Departments of ${ }^{1}$ Pediatrics and ${ }^{2}$ Ophthalmology, Kurume University School \\ of Medicine, 67. Asahi-machi, Kurume 830, Japan
}

\begin{abstract}
Summary Incidences of dystopia canthorum and some other signs were studied in a family with Waardenburg syndrome type I. When "W" index was used as a diagnostic parameter, dystopia canthorum was expressed in $88 \%$ of the family members who exhibited one or more of the signs, whereas incidence of this trait was calculated to be $63 \%$ or less, when the other indices were employed. Incidences of the other signs ranged from $50 \%$ to $13 \%$. These observations indicate that $\mathrm{W}$ index is the most sensitive indicator of dystopia canthorum, and that this characteristic is most frequently expressed among the signs of Waardenburg syndrome type I.
\end{abstract}

\section{INTRODUCTION}

Waardenburg syndrome (WS) is an autosomal dominant clinical entity characterized by dystopia canthorum (lateral displacement of the medial canthi), broad, prominent nasal root, synophrys, pigmentary anomaly of the skin, hair and iris, and congenital deafness (Waardenburg, 1951). Existence of each component of the clinical manifestations of this syndrome is variable, as is the case with many other autosomal dominant disorders. Expression of dystopia canthorum was, however, found to be neary complete $(99 \%)$ in Waardenburg's original series (1951). Therefore, this characteristic was considered to be an almost infallible indicator of the presence of this syndrome (Waardenburg, 1951).

Later studies revealed that this syndrome can be divided into two heterogeneous types, depending on the presence (type I), or absence (type II) of dystopia canthorum (Arias, 1971; Hageman and Delleman, 1977). It was reported that individuals with

Received May 28, 1986; revised version received August 9, 1986; Accepted October 30, 1986 Offprint request to: M. Yoshino, Department of Pediatrics, Kurume University School of Medicine, Asahi-machi, Kurume 830, Japan. 
equivocal, "nonapparent" dystopia canthorum can be identified by a graded biometic technique (Arias, 1971), and that expression of dystopia canthorum in WS type I is almost complete, if "nonapparent" dystopic individuals are included (Arias and Mota, 1978; Arias, 1980; Arias, 1984). Therefore, a quantitative estimation of dystopia canthorum is essential to the classification of WS. For the quantitative estimation of dystopia canthorum, several interocular indices; "L" (Cotterman, 1951), "X $+Y$ " (Arias, 1971), "W" (Arias and Mota, 1978), or palpebral fissure index (PFI) (Wang, 1972) have been devised and applied for this purpose.

In this paper we studied expressivity of each component characteristic in a family with WS type I, and found that calculated incidence of dystopia canthorum could be variable depending on each interocular index employed to diagnose dystopia canthorum.

\section{CASE REPORT}

Proband (85-2356), $I I I-1$

The proband was born to a 35 year-old primigravida mother after 40 weeks of gestation. Parents were not related. Birth weight was $3,254 \mathrm{~g}$. His prenatal and perinatal history was uneventful. He was referred to us for ophthalmologic evaluation at the age of four months because of bluish-gray color of left iris, which had been noticed immediately after birth. Physical examination at the age of four months revealed a well nourished boy with bluish-gray colored left iris, wide-based nasal root, and generalized, mild muscular hypotonia. He appeared to respond normally to verbal stimuli, but we were unable to test his auditory status. There were no other physical anomalies, such as pigmentary anomaly of the skin or hair, or cardiac anomalies. Laboratory studies revealed elevations of serum aspartate transaminase ( $87 \mathrm{Karmen}$ units), alanine transaminase (65 Karmen units), alkaline phosphatase (39 Bodansky units) and inorganic phosphate $(7.0 \mathrm{mg} / \mathrm{dl})$. These values declined to normal levels by five months of age. Other laboratory data, including complete blood count, urinalysis, blood gas analysis, serum aminogram, lactate dehydrogenase, choline esterase, $\gamma$-glutamyltranspeptidase, and zinc concentration were all normal. Karyotype was $46, \mathrm{XY}$.

\section{Father of the proband, $I I-8$}

Father of the proband was the product of uncomplicated pregnancy and fullterm delivery. Hypochromia of the left iris was noted at the time of birth, and premature graying of hair became prominent in his late childhood. He has noticed hearing difficulty and occasional tinnitus since late childhood. Physical examination which was made when he was 36 years of age revealed white forelock, hypochromia of the left iris, wide-based nasal root, and medial flaring of eyebrows. No pigmentary change of the skin was found. An audiometric study revealed a sensorineural hearing loss of the left ear. Routine laboratory studies disclosed no abnormal results. 


\section{METHODS}

Six family members in two successive generations, in addition to the proband and parents, were personally examined. Pedigree chart of this family is illustrated in Fig. 1.

Following function or indices were employed as criteria for quantitative diagnosis of dystopia canthorum; "L" function (Cotterman, 1951), "X+Y" (Arias, 1971; Preus et al., 1983), palpebral fissure index (Wang, 1972), and "W" index (Arias and Mota, 1978). These indices and function are derived from the following formulae.

$$
\begin{gathered}
\mathrm{L}=\mathrm{a}-0.2497 \mathrm{~b}-0.2119 \mathrm{c}-3.909 \\
\mathrm{X}+\mathrm{Y}=\frac{2 \mathrm{a}-(0.2119 \mathrm{c}+3.909)}{\mathrm{c}}+\frac{2 \mathrm{a}-(0.2497 \mathrm{~b}+3.909)}{\mathrm{b}} \\
\mathrm{W}=\mathrm{X}+\mathrm{Y}+\mathrm{a} / \mathrm{b} \\
\mathrm{PFI}=\frac{\mathrm{c}-\mathrm{a}}{2 \mathrm{c}}
\end{gathered}
$$

where, $a=$ inner canthal distance, $b=$ interpupillary distance, and $c=$ outer canthal distance, in millimeters.

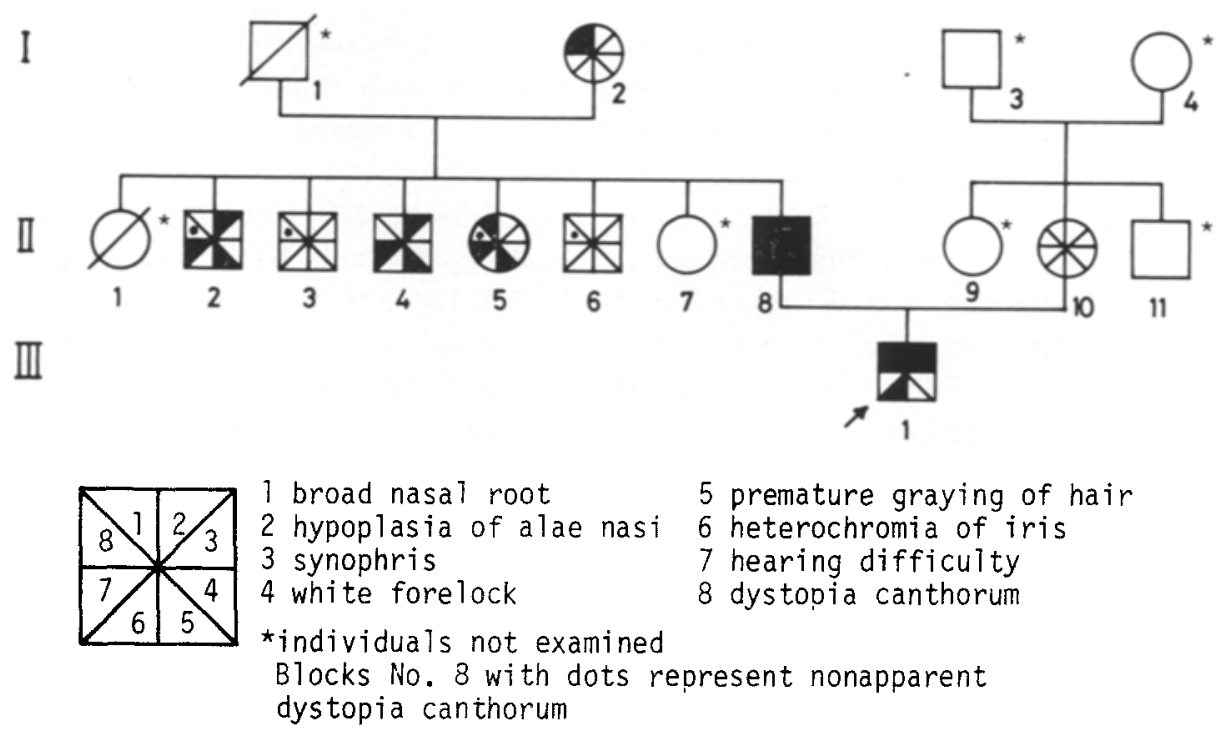

Fig. 1. Pedigree of the family. Cardinal characteristics of the syndrome are allotted to respective eight-divided blocks in each symbol. Open blocks indicate absence, and closed blocks, presence of the individual signs. 
A value of $L$ falls in a positive range in dystopic individuals, whereas a negative $L$ value implies nondystopic (Cotterman, 1951). An $X+Y$ value of 1.55 or more is indicative of the syndrome (Preus et al., 1983). A W index value of 2.07 or more is diagnostic of apparent dystopia canthorum, and a value of $\mathrm{W}$ index which is over 1.87 and less than 2.07 is considered to represent nonapparent dystopia (Arias and Mota, 1978). PFI value varies from 0.20 to 0.30 in individuals with dystopia canthorum (Wang, 1972).

\section{RESULTS}

Values of the measurements of the interocular distances, index figures, and discriptions of the clinical features of each individual are summarized in Table 1. The paternal grandmother (I-2) of the proband (IlI-1), had apparent dystopia canthorum, as determined on the basis of the index values (Table 1). This woman, however, did not have any other component of WS, except broad nasal root. The other four individuals, II-2, II-3, II-5 and II- 6 exhibited borderline values of W index which fell within the respective ranges of nonapparent dystopia canthorum. There was one family member (II-4) who showed normal values of the interocular indices, but had some of the other characteristics of WS. Two of the family (II-2 and II-3) had been diagnosed to have diabetes mellitus, and II-5 has had intermittent mellituria. Another individual, II-6, had none of the WS signs, barring nonapparent dystopia canthorum (W index value, 1.90). Paternal grandfather (I-1), who had died before this study, was reported to have had none of the apparent features of WS. The family members of the generation III, with the exception of the proband, were excluded from the study, as they were not personally examined. There were no maternal family members who showed characteristics suggestive of WS.

Incidences of each sign in eight family members in whom one or more of the WS signs are expressed (I-2, II-2 through II-6, II-8 and III-1) are summarized in Table 1. Out of these eight members, three (I-2, II-8 and III-1) had apparent dystopia canthorum, and the other four (II-2, II-3, II-5 and II-6) had nonapparent dystopia canthorum, when diagnosis of the eye anomaly is made on the basis of the $\mathrm{W}$ index values. Thus, the overall incidence of dystopia canthorum (apparent and nonapparent combined) in these family members was calculated to be $88 \%$. Lower incidence figures were given, however, when the other ocular indices were employed. The incidences of the other signs were lower, with white forelock being least frequent.

\section{DISCUSSION}

The proband and father in the present family can be classified as having WS type I. Among the main clinical features of WS, dystopia canthorum shows a high degree of distinct expression (Waardenburg, 1951). Therefore, identification of this trait is of particular diagnostic value in otherwise equivocal cases. 


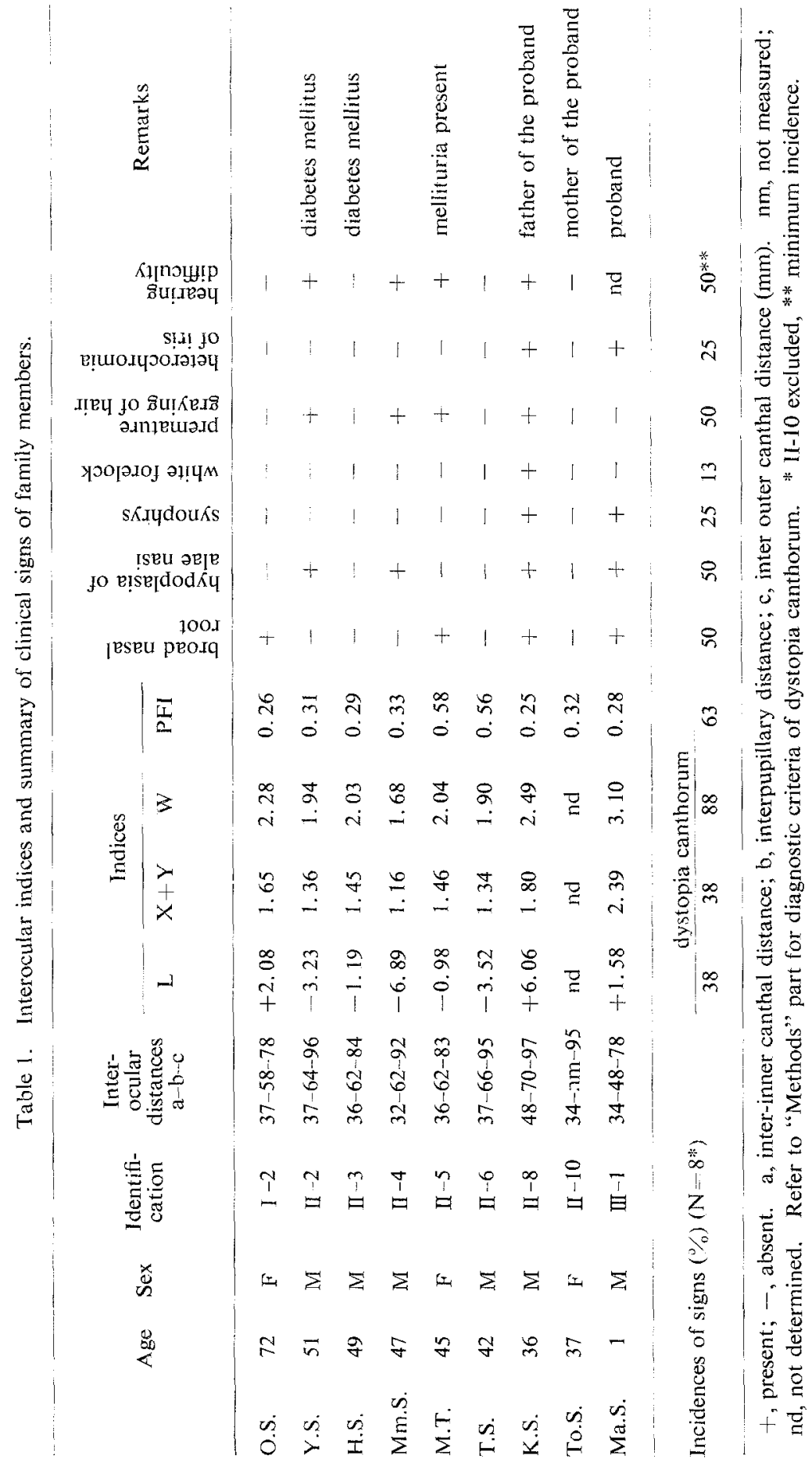


It is noteworthy that in only two (I-2 and II-8) of the family members, excluding the proband, the values of $\mathrm{L}$ and $\mathrm{X}+\mathrm{Y}$ fell within the respective ranges of dystopia canthorum (Table 1). Estimation of the incidence of dystopia canthorum on the basis of these indices gives lower incidence figures than what can be calculated on the basis of the $\mathrm{W}$ index value (Table 1). These results demonstrate that $\mathrm{W}$ index is more sensitive indicator than the other indices to differentiate dystopic individuals from nondystopics and that use of $\mathrm{W}$ index is thus validated to estimate expressivity and penetrance of dystopia canthorum.

The incidence of dystopia canthorum $(88 \%)$ was higher than those of the other signs (Table 1). This result is compatible with the previous observations (Waardenburg, 1951; Hageman and Delleman, 1977; Preus et al., 1983; De Saxe et al., 1984). In contrast with the other paternal family members, II-4 was not interpreted to have dystopia canthorum on the basis of the eye measurements, although he had some other characteristics of WS (characteristic nose, premature graying of hair, and hearing difficulty) as given in Table 1. This individual was considered to be a gene carrier of WS type I without dystopia canthorum. When nonapparent dystopia canthorum is included, nonexpression for dystopia canthorum in WS type $I$ is extremely rare, but it does occur in less than five $\%$ of WS type I individuals (Arias, 1971).

Two family members (II-2 and II-3) had diabetes mellitus, and one (II-5) had intermittent mellituria. It is unclear whether or not diabetes mellitus is the product of a pleiotropic expression of WS type I.

\section{REFERENCES}

Arias, S. 1971. Genetic heterogeneity in the Waardenburg syndrome. Birth Defects: Original Article Series 7: 87-101.

Arias, S. and Mota, M. 1978. Apparent non-penetrance for dystopia in Waardenburg syndrome type I, with some hints on the diagnosis of dystopia canthorum. J. Genet. Hum. 26: 103-131.

Arias, S. 1980. Letter to the editor: Waardenburg syndrome-two distinct types. Am. J. Med. Genet. 6: 99-100.

Arias, S. 1984. Letter to the editor: Diagnosis and penetrance of dystopia canthorum in Waardenburg syndrome type (WS1). Am. J. Med. Genet. 17: 863-865.

Cotterman, C.W. 1951. Some statistical problems posed by Waardenburg's data on dystopia canthorum and associated anomalies. Am. J. Hum. Genet. 3: 254-266.

De Saxe, M., Kromberg, J.G.R., and Jenkins, T. 1984. Waardenburg syndrome in South Africa. Part I. An evaluation of the clinical findings in 11 families. S. Afr. Med. J. 66: 256-261.

Hageman, M.J. and Delleman, J.W. 1977. Heterogeneity in Waardenburg syndrome. Am. J. Hum. Genet. 29: 468-485.

Preus, M., Linstrom, C., Polomeno, R.C., and Millot, J. 1983. Waardenburg syndrome-penetrance of major signs. Am. J. Med. Genet. 15: 383-388.

Waardenburg, P.J. 1951. A new syndrome combining developmental anomalies of the eyelids, eyebrows and nose root with pigmentary defects of the iris and head hair and with congenital deafness. Am. J. Hum. Genet. 3: 195-253.

Wang, D.H. 1972. Waardenburg syndrome. Leech 42: 23-27. 